\title{
Overfeeding in infancy
}

\section{By L. S. TAITZ, Department of Child Health, University of Sheffield, Western Bank, Sheffield io}

Several studies have drawn attention to the potential dangers inherent in the excessive intake of energy and solute loading in newborn and young infants (Eid, 1970; Oates, 1973). It is only comparatively recently that these problems have become manifest (British Medical Journal, I973), partly because the doctrine that 'one cannot overfeed a young infant' has died hard, and partly because they are the consequences of the increasing use of full-cream cow's milk formulas for the artificial feeding of infants, supplemented, at an early age, with solid material. It is important to recognize that it is not merely a question of excessive intakes of energy and solutes as such. The detailed character of the solute and its composition is equally important, as is the effect of such changes on the water intake, and therefore the external water balance of the infant. Our own interest in this topic was first aroused by the observation of a very high incidence in this country of hypernatraemic dehydration in children with gastroenteritis. The reported incidence (Ironside, Tuxford \& Heyworth, I970) of this complication (63\%) is three times higher than that quoted in the American literature (Finberg, 1969) where most of the original work on hypertonic dehydration was reported. It occurred to us that this might be in some way bound up with the tendency for babies in this country to be given milk formulas composed of full-cream cow's milk, as opposed to the United States where either evaporated full-cream cow's milk is used, or, alternatively, relatively lowsolute feeds resembling breast-milk are given. We were also interested in the apparently excessive rate of weight gain manifested by young infants returning to the well-baby clinic at the Jessop Hospital (Taitz, 1971; Taitz \& Harris, 1972). The third observation that we thought striking was the fact that many mothers were starting cereals and even meat and other baby foods as early as the first week of life. In order to elucidate the nature of the intake of the infants that we were studying, we obtained a series of random urine samples from breast-fed and artificially fed babies at the age of 6 weeks, and also of milk that the mothers had prepared to feed their babies when they brought them to the clinic. The results of these investigations have been reported elsewhere (Taitz \& Byers, 1972), but are summarized in the accompanying table (Table $r$ ). What we have demonstrated is that the concentrations of creatinine and uric acid in the urine of breast-fed babies compared with babies fed on cow's milk formulas indicate that the urine volume of the latter group is considerably lower than one would normally expect. We have also shown, as expected, that the solute excretion of breast-fed babies is much lower than that of artificially fed infants. Attention has recently been drawn once again to the high solute load of cow's milk feeds (Shaw, Jones \& Gunther, I973). We have also been 
Table r. (a) Mean osmolarity and concentrations of creatinine and uric acid in the urine of 6-week-old infants

Creatinine (mmol/1)

Uric acid (mmol/1)

Osmolarity (mosmol/l)

Breast-fed
(BF)
$0 \cdot 70$
$0 \cdot 72$
$104^{\circ} \circ$

Artificially fed
$($ AF $)$
$\mathrm{I} \cdot 42$
$\mathrm{I} \cdot 62$
$377 \cdot 9$

Ratio
AF:BF
$2 \cdot 04$
$2 \cdot 26$
$3 \cdot 63$

(b) Mean sodium concentration in feeds prepared from dried-milk products

\begin{tabular}{lccccc} 
& $\begin{array}{c}\text { Mean Na } \\
\text { concn } \\
(\mathrm{mmol} / \mathrm{l})\end{array}$ & \multicolumn{2}{c}{ No. of feeds with Na concn $(\mathrm{mmol} / \mathrm{l}):$} \\
\cline { 3 - 6 } & $<25$ & $25-30$ & $30-35$ & $>35$ \\
Prepared by mothers & 31 & 2 & 9 & 14 & 6 \\
Prepared in laboratory & 26 & - & - & - & -
\end{tabular}

able to demonstrate that the concentration of the milk formula that these babies are given is considerably higher than it should be, and that the cause of this is a combination of errors due directly to the mistakes made in preparing the formula. Most of these errors relate to incorrect filling and preparation of scoops used to measure the milk powder (Taitz, I973). Some of the more common mistakes which have been identified are: heaped milk-powder scoops, packing down scoops, extra scoops of powder, too little water in the feed, rusks crumbled in the feed, addition of cereals to bottle feeds and early additions of high-solute solids to the diet. This error is of the order of $25 \%$ on average. Other studies have confirmed this tendency to make up feeds which are too concentrated (Wilkinson, Noble, Gray \& Spence, I973).

\section{Factors which influence water and energy intake}

It is necessary at this point to discuss briefly the factors which appear to control the normal intake of water, energy and solute by infants. There appear to be two main mechanisms which are important. The first, or primary mechanism, is that controlled by the energy intake. Ziegler \& Fomon (I97I) have pointed out that the major factor in deciding the volume of food that an infant takes, when it is in a state of normal external water balance, is the energy concentration of the food. The baby's response to hunger will enable him to take food until he has satisfied his energy requirements. Thus if an infant is offered a more concentrated food, he will take a smaller volume than if offered a less concentrated one. The secondary mechanism, that of thirst, appears to apply where there is a deficit in the external water balance. This presumably only becomes dominant when the infant becomes dehydrated, with consequent shifts in body water compartments.

Effect of varying energy : solute : water ratios on body water compartments and external water balance in normal infants

In Figs I-4, an attempt has been made to illustrate the possible effects of alterations in energy: solute: water ratios on these factors. Fig. I illustrates the 
normal situation, in which it is assumed that a normal healthy infant requires about $460 \mathrm{~kJ}$ (I I $\mathrm{kcal}$ ) $/ \mathrm{kg}$ per $\mathrm{d}$. This amount of food is supplied by $150 \mathrm{ml}$ milk, either human or cow's, and the infants' intake of either of these is usually adjusted to a level of about $150 \mathrm{ml} \mathrm{milk} / \mathrm{kg}$ per $\mathrm{d}$. Under these circumstances, the intracellular

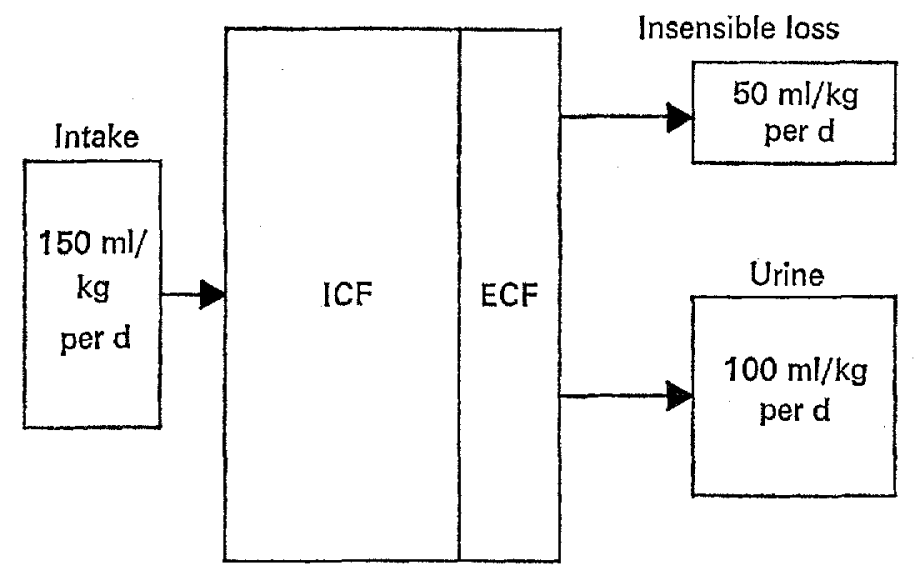

Fig. I. Body water compartments and external water balance of a normal, healthy infant, assumed to be receiving about $460 \mathrm{~kJ}$ ( 1 ro kcal)/ $\mathrm{kg}$ per d as milk. ICF, intracellular fluid; ECF, extracellular fluid.

fluid (ICF) space and extracellular fluid (ECF) space are maintained at normal levels and this is accompanied by certain water losses, particularly insensible loss, of the order of $50 \mathrm{~m} 1 / \mathrm{kg}$, with urine accounting for most of the rest. For simplification here, urine volume has been stated as $100 \mathrm{ml} / \mathrm{kg}$ per $\mathrm{d}$, but obviously over a period of time some of this fluid is retained in the normal accretion of tissue for growth. Fig. 2 illustrates the effect of raising the energy: water ratio by $25 \%$. In this model it is assumed that the osmolar or solute load remains unchanged. This is the effect that

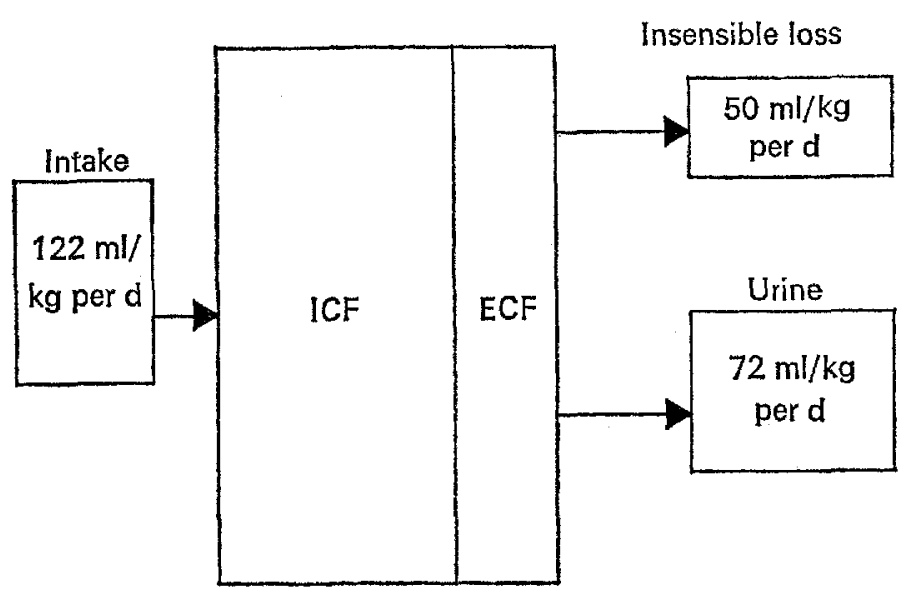

Fig. 2. Body water compartments and external water balance of an infant receiving milk which has been fortified with starch or sugar to provide an extra $25 \%$ energy. ICF, intracellular fluid; ECF, extracellular fluid. 
will be produced by adding pure starch or sugar to the babies' milk formula. In this situation there are $577 \mathrm{~kJ}$ ( $138 \mathrm{kcal}$ ) per $\mathrm{I} 50 \mathrm{ml}$ of fluid. Increasing the energy content would, under normal circumstances, lead to a reduction in the volume of intake to around $122 \mathrm{ml} / \mathrm{kg}$ per d. The ICF space and the ECF space are maintained at a normal level. Insensible loss continues as before at around $50 \mathrm{ml} / \mathrm{kg}$ per d, but urine volume is reduced to around $72 \mathrm{ml} / \mathrm{kg}$ per $\mathrm{d}$. The urine osmolarity will be somewhat increased since the osmolar excretion remains unchanged. Fig. 3 illustrates the effect of solute loading but with a normal energy:water ratio. This is a situation that would result from a simple addition of sodium chloride to the infants' feed. The energy content of the food remains unchanged, at the normal composition of $460 \mathrm{~kJ}$ (I IO kcal) per $150 \mathrm{ml}$ per d. The infants' water intake, therefore, is fixed at this level. The ICF space remains unchanged but it is probable that the ECF space will become expanded. This will, to a large extent, depend on the ability of the infant

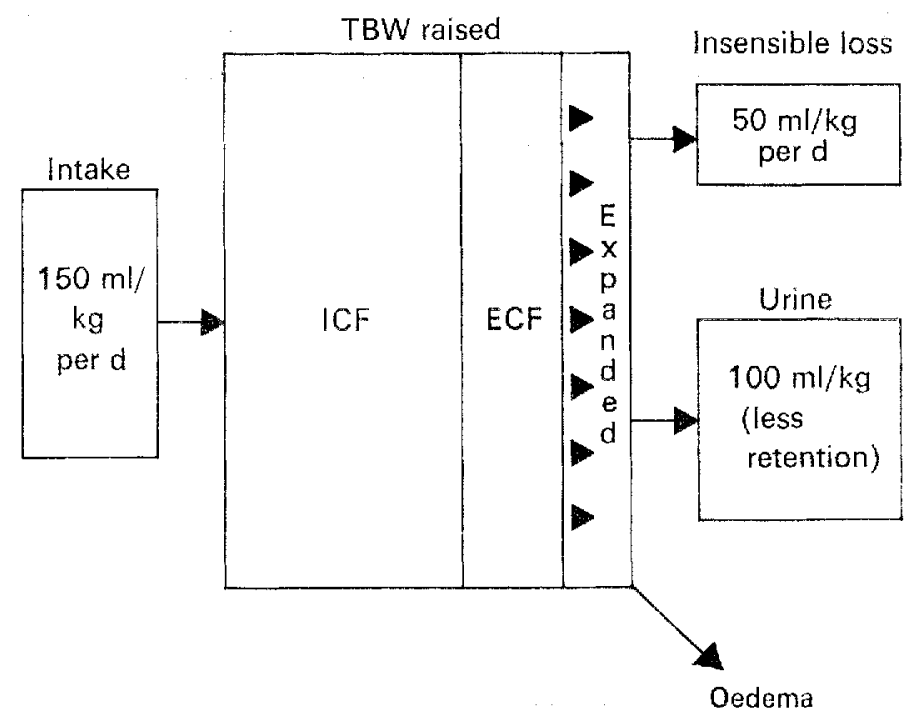

Fig. 3. Body water compartments and external water balance of an infant receiving milk containing extra solute $(\mathrm{NaCl})$, but no extra energy. TBW, total body water; ICF, intracellular fluid; ECF, extracellular fluid.

kidney to excrete an additional $\mathrm{Na}$ load, a function for which it is not very well equipped. Under these circumstances it is to be expected that there would be a degree of $\mathrm{Na}$ retention. This would eventually lead to water retention with a fall in urine volume and ultimately to the development of oedema. The body osmolar concentration would be unchanged. This accounts for the fact that the ICF volume remains the same. These infants are unlikely to be thirsty, and therefore would not indicate that anything was amiss. They would not increase their demand for food, so there would be no true increase in total body solid mass. Fig. 4 illustrates what might happen when there is both Na loading and a high energy:water ratio. This is the state of affairs that is seen in the infants that we have described, since the adding of excessive quantities of milk powder to the infants' formula would lead to a rise in 


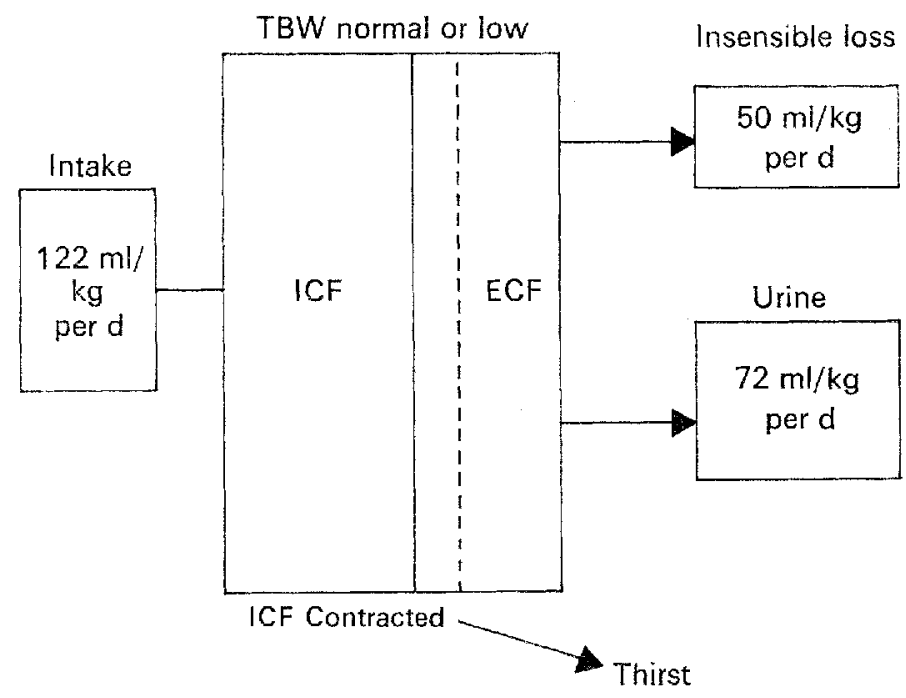

Fig. 4. Body water compartments and external water balance of an infant recciving milk containing extra solute and $25 \%$ extra energy. TBW, total body water; ICF, intracellular fuid; ECF, extracellular fluid.

both the solute load and its energy content. The probable effects of this are very interesting. In the first place one would expect the infant to reduce its water intake to around $122 \mathrm{ml} / \mathrm{kg}$ per $\mathrm{d}$, something which we have already shown probably occurs. There is thus a situation in which a high solute load is combined with a reduced water intake, the classic combination of events leading to hypertonicity of the ECF. This hypertonicity would lead to an alteration in the body water compartments with a contraction of the ICF space and an expansion of the ECF space. Urine volume would be reduced to around $72 \mathrm{ml} / \mathrm{kg}$ per d. It would be expected that under these circumstances the infants would evince the symptoms of thirst because of intracellular dehydration. There would be little or no evidence of classic dehydration in these children because the ECF is usually normal. The misinterpretation of this symptom of thirst would lead to continued overfeeding of these infants, with the temptation to introduce solid foods with a further increase in energy intake, and consequently to obesity. The infants are then subject to excessive weight, excessive fat, a contracted ICF volume and a normal or expanded ECF volume. This is the situation that we think applies to the infants that we have described. Recent studies tend to confirm that the extracellular osmolarity in these infants is indeed raised and that they are in a mild state of chronic hypertonicity (Davies, I973). It is obvious that these infants are, as far as the external water balances are concerned, in a perilous situation. The urine volume is reduced and yet the kidneys have to excrete an extremely high osmolar load. The water intake is reduced to well below a safe margin, and any excessive losses occurring thereafter, either from diarrhoea or fever, or from hyperventilation, could produce a sudden and catastrophic change in the extracellular osmolarity. It seems likely that it is this factor that accounts for the present high incidence of hypertonic dehydration. 


\section{Summary}

It seems likely that the excessive solute-energy loading of young infants has two effects. The first is to produce a situation of chronic mild hypertonicity of the ECF, a contraction of ICF volume and a consequent tendency for chronic thirst leading to overfeeding and obesity. Secondly, in this situation there is always the risk of sudden alteration in external water balance leading to a catastrophic increase in ECF osmolarity and to hypertonic dehydration.

\section{REFERENCES}

British Medical Journal (1973). Br, med. $\mathcal{F} . \mathrm{ii}, 727$.

Davies, D. P. (1973). Br. med. F. ii, 340 .

Eid, E. E. (1970). Br. med. $\%$. ii, 74 .

Finberg, L. (1969). Yb. Pediat. 37, 49 .

Ironside, A. G., Tuxford, A. F. \& Heyworth, B. (r97o). Br. med. F. ii, 20.

Oates, R. K. (1973). Br. med. 7 . ii, 762 .

Shaw, J. C. L., Jones, A. \& Gunther, M. (1973). Br. med. F. ii, 12.

Taitz, L. S. (1971). Br. med. F. i, 315.

Taitz, L. S. (1973). Proc. Br. Nutr. Res. Conf., Cambridge, 1973 (In the Press.)

Taitz, L. S. \& Byers, H. D. (1972). Archs Dis. Childh. 47, 257.

Taitz, L. S. \& Harris, F. (1972). Acta paediat., Stockh. 6r, 499.

Wilkinson, P. W., Noble, T. C., Gray, G. \& Spence, O. (1973). Br. med. F. ii, I5.

Ziegler, E. E. \& Fomon, S. J. (1971). F. Pediat. 78, $56 \mathrm{I}$. 